\title{
Apoptosis Inducer MPC-2130
}

National Cancer Institute

\section{Source}

National Cancer Institute. Apoptosis Inducer MPC-2130. NCI Thesaurus. Code C64781.

A broad-acting, apoptosis-inducing, small molecule with potential antineoplastic activity. Although the exact mechanism of action has yet to be fully elucidated, apoptosis inducer MPC-2130 exhibits proapoptotic activities in tumor cells, including membrane phosphatidylserine externalization, release of cytochrome C from mitochondria, caspase activation, cell condensation, and DNA fragmentation. In addition, because this agent is not a substrate for several types of multidrug resistance (MDR) ABC superfamily transporters, such as P-glycoprotein 1 (MDR-1), multidrug resistance-associated protein 1 (MRP1), and breast cancer resistance protein 1 (BCRP1/ABCG2), it may be useful in treating MDR tumors that express these particular MDR efflux pumps. 